gurgling could be canght; the complete immunity of the lungs fixed the dependence of the symptoms upon disease within the pericardium, and although the other symptoms may have been adequate to the diagnosis of effusion, they were necessarily of so equivocal a character that it was satisfactory to have them corroborated by so valuable a sign as gurgling. The trivial amount of disturbance caused by so serious an affection was very remarkable; he had actually been mowing for two hours on the day before $I$ examined him, and could walk for a few miles at a slow pace; but to walk quick for twenty paces would cause the most distressing dyspncea; and this explains a very important fact, that proved the stumbling-block to the correct diagnosis of many thoracic diseases before the introduction of the stethoscope. When a person formerly suffered from embarrassed breathing and dropsical symptoms, hydrothorax was considered to be the first link in the diseased chain; but we now know that it is the very last, and that disease of the heart is the primary onedisease of the heart producing a relative disproportion between the contents of its cavities. In hydropericardium, this relative disproportion cannot exist, as all parts of the heart sustain equal pressure, and it is only by sending the blood too quickly to the heart that the dyspnoea is rendered distressingly apparent. The intelligent gentleman under whose care the case was, adopted the same view of it that I did. He treated the case by cupping, mercury, and counter-irritation, with complete success.

Hydrometra.-On Tuesday last, I had occasion to make a stethoscopic examination in a case of obscure uterine enlargement, in which I was assisted by Mr. Morris of this town. We were unable to detect any placental or fœtal murmurs; but the gurgling of fluid was so distinct that it arrested the attention of both of us, quite independent of each other; the motion appeared to have been imparted to the fluid by the descent of the diaphragm, and the contraction of the abdominal muscles. I mention this case, as the hint may be serviceable in otber cases, where it may be difficult to diagnose the presence of effusionno usual circumstance in cases of ascites, accompanied by a deposition of cellular tissue in the abdominal walls.

September, 1845.

\section{CASE OF HYDATID TUMOURS IN THE ABDOMEN AND PELVIS.}

By JoHv Monley, Esq. Surgeon, Burton-upon-Humber.

JoHs G__, aged thirty-eight, waterman, of sallow complexion, first consulted me on September 8th, 1843, on account of spasmodic affection of the stomach, to attacks of which he has been subjected for many years. He was relieved by the medicine that was administered, in the course of about a fortnight, and $I$ did not see him again until

May 24th, 1845, when he applied to me on account of great enlargement of the abdomen, which had increased very rapidly of late, so as to prevent him following his occupation. He states that he has always been high-bodied; his general appearance is much altered since I last saw him; countenance more sallow and cachectic. He complains of sickness, flatulence, and constipation of bowels ; is unable to walk far, on account of dyspnoea; pulse quick and weak; urine small in quantity, almost limpid, and of low specific gravity, being only 1.07 at a temperature of $84^{\circ}$ Fah., not coagulable by heat or nitric acid. On examination of the abdomen, whilst lying on his back, a large tumour was perceived, extending from the epigastric and left hypochondriac to the upper margin of the pubic region, inclined towards the left side, measuring at its greatest circumference thirty-seven inches. The space occupied by the tumour was dull on percus. sion. The right hypochondriac and lumbar regions sounded remarkably clear. I tried the effect of hydriodic acid and aperients for about a month, without benefit. In the beginning of July his abdomen became more enlarged, and he was very drowsy, his urine contained a deposit, which was convoluted, about the length and thickness of a crow's quill; it looked like pus or semen.

July 16 th. - He was attacked this morning with an epileptic fit, which lasted half an hour. Mr. William Eddie visited him in my absence, and ordered twelve leeches to be applied to the temples, sinapisms to the calves of the legs, and purgatives.

17 th. - Is more comatose, being almost always asleep, although easily aroused. Passes but little urine. Applied a blister to the nape of the neck.

19th.-Dr. Alderson visited him, and confirmed our opinion that this was most probably a case of hydatid tumour; suggested the idea that it might possibly be a simple cyst, and advised that the tumour be punctured.

20th, eleven A.M.-Mr. William Eddie visited him with me, and after a careful examination of the case, concurred as to the propriety of the operation proposed by Dr. Alderson. A trocar was introduced at the. linea alba, on withdrawing which the canula became obstructed with the coats of hydatids; the incision was prolonged about two inches, which permitted two washhandbasinfuls of bydatids to escape, varying from the size of a hen's egg to that of small peas. These were perfectly transparent whilst warm; there were also myriads of broken-down cysts, some of which were reduced to a pultaceous mass. He bore the operation remarkably well; the wound was closed by the quilled suture, and a bandage applied. He took, an hour afterwards, half a pint of gruel, expressed himself comfortable, and said he should soon be right. In the course of an hour he became comatose, and could not be aroused.

21 st, ten A.M. - Lies on his back, breathing with an apoplectic stertor; has frequent spasmodic twitches of the muscles; pulse 120, full and bounding; jugular veins distended and pulsating; has passed no urine since the operation. There has been a great discharge of fetid matter from the urethra.-Quarter to five P. M. On visiting him this afternoon, to introduce the catheter, I found it impossible to do so, on account of an obstruction to its entrance into the membranous portion of the urethra. About five minutes after the attempt he was seized with convulsions, and expired in a few moments.

Examination twenty-three hours after Death.-On exposing the abdominal viscera, a cyst was perceived to the left of the linea alba, extending from the diaphragm to the iliac fossa, situated within the folds of the omentum, in front of the spleen and kidney ; it was adherent to the peritoneum by false membrane throughout its whole extent; from its lower portion a narrow band passed off to another cyst, situated between the bladder and rectum; the larger tumour contained a few entire hydatids, with about a quart of débris. Its inner surface was rough and cartilaginous. On the posterior part of its outer coat was a tumour, as large as a walnut, which contained the dry skins of hydatids, firmly packed together. The lower cyst completely filled the pelvic cavity, mounting upwards into the abdomen, and appeared ready to burst ; it pressed on the rectum and bladder, so as to displace the latter, and accounted for the difficulty whilst attempting to introduce the catheter. Its cavity was lined by one large hydatid, the inner coat of which was very rough, and contained about a dozen small transparent ones.

The bladder contained about two ounces of turbid urine.

Ureters dilated.

Left kidney enlarged to twice its natural size; hard and lobulated; its pelvis enormously dilated, containing urine.

Right kidney dilated into a large sae; its secretory portion did not appear more than half an inch in thickness.

Spleen small, and softened; stomach and bowels did not present any morbid appearance, with the exception of the rectum, which was much contracted.

Liver congested.

The Gall-bladder contained two calculi, around which it was firmly contracted; one of these weighed sixty-four grains, the other ten.

Chest.-Pleuræ universally adherent; lungs congested; heart dilated and flabby.

The head was not permitted to be examined.

\section{ON THE TREATMENT OF DISEASES OF THE} MIDDLE AND IN'TERNAL EAR.

(Translated from the French by Dr. JoH ston.)

The following paper was read before the Royal Academy o Sciences at Paris, by Dr. Wolff, of Berlin, on the 6th of January, 1845 :-

The most recent advance in otiatrics is, beyond a doubt, indicated by the introduction of aërial substances, instead of liquid injections, into the Eustachian tube. M. Deleau was the first to whom this improvement may be attributed. It was he who first demonstrated the inconvenience of liquid vehicles and the advantage of aërial substances, which, from their gaseous condition, are analogous to the air which circulates in the middle ear, and from that very circumstance, much better suited for introduction into the cavity of the tympanum.

But, on the other hand, it must not be forgotten, that aqueous injections have certain advantages over the douche of air-advantages which seem to have been entirely lost sight of by the majority of aurists since aqueous injections have been replaced by the air-douche.

Water is the principal vehicle for almost all medical substances. In nature, as in art, it is the fluidem solvens of the greater part of them. By means of aqueous injections, then, many remedies can be introduced into the middle ear. Thus, Itard injected Barêge water, saline and aromatic solutions. 